\title{
(Neo)chamanismo. Aspectos constitutivos y desafíos analíticos
}

\section{(Neo)shamanism. Constitutive aspects and analytical challenges}

\author{
Juan Scuro* \\ *Universidad de la República - Montevideo, Uruguay \\ Posdoctorado en curso (becario CAP) \\ juanscuro@gmail.com
}




\title{
Resumen
}

Se analizan las principales continuidades y rupturas entre chamanismo y neochamanismo, describiendo las formas a través de las cuales se han construido unas imágenes del Otro chamán, poderoso, en relación específica con las ideas de Naturaleza y Cura. Se plantea que las plantas maestras son el paradigma de la intersección de ambos componentes y la más eficaz técnica seductora y expansionista del neochamanismo, observado en el marco de las dinámicas propias de la modernidad/colonialidad. Finalmente, el texto presenta algunas estrategias discursivas específicas dentro del ámbito neochamánico o de uso de plantas maestras que obligan a refinar y profundizar los análisis sobre el neochamanismo.

Palabras clave: chamanismo; neochamanismo; plantas maestras; Nueva Era.

\begin{abstract}
The main continuities and ruptures between shamanism and neo-shamanism are analyzed, describing the forms through which images of the shamanic Other, powerful, have been constructed in specific relation with the ideas of Nature and Healing. It is argued that the teacher plants are the paradigm of the intersection of both components and the most effective, seductive and expansionist technique of neo-shamanism, observed within the framework of the dynamics of modernity/coloniality. Finally, the text presents some specific discursive strategies within the neo-shamanic domain that force to refine and to deepen the analyses on the neo-shamanism.
\end{abstract}

Keywords: shamanism; neo-shamanism; teacher plants; New Age. 


\section{Introducción}

Es cada vez más notoria la expresión de prácticas chamánicas en ámbitos que desbordan a aquellos donde se han desarrollado los chamanismos "tradicionales". Prácticas chamánicas han ido siendo incorporadas gradualmente en ámbitos urbanos, muchas veces lideradas por personas con trayectorias de vida ajenas al chamanismo. Actualmente no es difícil tener acceso a ceremonias/retiros/sesiones chamánicas que ganan popularidad en ámbitos urbanos y entre sectores medios y medios altos instruidos. A este proceso se lo puede identificar como "chamanismo urbano" o "neochamanismo".

En este texto veremos algunas características fundamentales del (neo) chamanismo. El paréntesis en el prefijo "neo" quiere dar cuenta de las continuidades que pueden ser observadas entre esos ámbitos. En primer lugar, se propone una breve caracterización del neochamanismo para dar paso luego a profundizar en dos aspectos que se han construido como constituyentes del (neo)chamanismo: una particular concepción acerca de la Naturaleza (en sentido ontológico); y una relación específica con mecanismos de cura diferentes a los comúnmente conocidos dentro de la medicina alopática. Luego de considerar estos "pilares" el texto ejemplifica cómo el uso de las plantas maestras, herramientas por excelencia del (neo)chamanismo, son paradigmáticas de la unión de esas dimensiones, constituyéndose en el más eficaz mecanismo de seducción dentro del neochamanismo. Allí se problematizan las continuidades para privilegiar el análisis de las rupturas (con las supuestas fuentes chamánicas originales) y transformaciones al interior del neochamanismo. Esto nos obliga a refinar y profundizar los mecanismos analíticos del fenómeno en estudio.

\section{Neochamanismo}

En Shamanism today, Jane Atkinson (1992) llamaba la atención respecto al proceso de reemergencia del tema, dado, entre otras cosas, el interés multidisciplinar por las temáticas de la consciencia, de los mecanismos terapéuticos y por el fuerte interés en las formas alternativas de espiritualidad. En la revisión que la autora hace de la literatura sobre el tema, observa dos preocupaciones 
dominantes: una relacionada a los aspectos psicológicos del propio chamán y otra centrada en el valor terapéutico de la cura chamánica. En lo que respecta a la primera tendencia los abordajes han centrado la atención en la cuestión del trance y de los estados modificados de conciencia, al punto de identificar al chamanismo y estos estados prácticamente como sinónimos. En relación a la segunda tendencia Atkinson observa la influencia del propio sistema biomédico y de la interdependencia de estos sistemas. ${ }^{1}$

Para Atkinson, el neochamanismo o chamanismo urbano presenta en las décadas de 1980 y 1990 (y yo agregaría, muy especialmente a partir de los años 2000) lo que el budismo y el hinduismo ofrecieron en las décadas precedentes. Siguiendo a esta autora, el neochamanismo se caracteriza por un apelo de las cualidades democráticas que evaden las jerarquías institucionalizadas. El nuevo chamanismo, continúa, es compatible con el énfasis contemporáneo en la autoayuda y los resultados inmediatos (Atkinson, 1992, p. 322), lo que va de la mano de Thomas DuBois (2009), cuando sugiere que el neochamanismo debe más a las expectativas de blancos de clase media que al propio chamanismo stricto sensu.

Alice Beck Kehoe prefiere pensar en términos de espiritualismo ecléctico para describir las prácticas de los sujetos de clase media, formados, que se piensan a si mismo como en un continuo crecimiento espiritual y que entienden que las iglesias institucionalizadas de sus padres no los proveen de la experiencia transformativa que ellos buscan, recurriendo, entonces, al neochamanismo. En este sentido la autora se pregunta por qué estos sujetos no buscan estas experiencias en el campo, por ejemplo, pentecostal, donde se habla en lenguas, se danza, se tienen visiones, etc. (Kehoe, 2000, p. 85). Aquí, evidentemente, entra en juego un componente de clase social que debe ser profundizado y donde posibles estudios comparativos puedan arrojar luz

1 Este es un punto importante para el desarrollo del neochamanismo en tanto espacio de encuentro de saberes, prácticas e imaginarios provenientes de fuentes diversas. Además de ser un cruce de técnicas, la superposición de los sistemas biomédicos con los chamánicos es un proceso de legitimación y al mismo tiempo de expansión de un conjunto de nuevas posibilidades terapéuticas. Estas otras terapéuticas que provienen de una alteridad vista como potencial de cura, como lo han analizado, por ejemplo, Michael Taussig (2012) y Alhena Caicedo (2007). 
sobre las especificidades y diferencias que hacen atractivos los diferentes ámbitos espirituales en función de los espacios sociales que se ocupan. El campo pentecostal (y principalmente neo-pentecostal), de evidente crecimiento en cuanto a popularidad y presencia pública, atrae a sectores sociales que no se ven necesariamente atraídos por la estética y retórica del neochamanismo. Las diferencias con los dogmas cristianos y la utilización de sustancias modificadoras de la conciencia (drogas) como enteógenos (sacramentos) en los ámbitos neochamánicos, establecen claras distancias entre los campos, digamos, (neo)pentecostal y (neo)chamánicos. Por otra parte, otros ámbitos donde se utilizan plantas medicinales o se realizan prácticas que podrían ser cercanas al neochamanismo, como en cierto curanderismo practicado por rezadores/as, aparece de forma más clara el componente y la simbología cristiana, lo cuál, en buena medida, es una de las direcciones hacia la cual, quienes circulan por los ámbitos neochamánicos, no necesariamente quieren dirigirse. Prevalece en el neochamanismo una búsqueda y atracción por alteridades más lejanas y exotizadas que aquellas internas conocidas. Este es un aspecto importante que sitúa al neochamanismo dentro de la llamada Nueva Era (incluso como marcador de clase social) y lo hace paradigmático de una modernidad/colonialidad donde la búsqueda de la emergencia de epistemologías otras está condicionada a su incorporación antropófaga a la modernidad capitalista dominante.

Kocku von Stuckrad (2002), en vez de neochamanismo, opta por el término "modern western shamanism". Tanto Atkinson como Stuckrad identifican en el neochamanismo o chamanismo occidental moderno, un común denominador relacionado a unos discursos y prácticas de "retorno a la naturaleza". Por otra parte, Stuckrad (2002, p. 791) coloca el énfasis en la influencia europea respecto a la relación del neochamanismo con la naturaleza y subraya que, en vez de tratarse de una degeneración híbrida de las culturas indígenas o un bricolage de espiritualidades, los chamanismos modernos occidentales (neochamanismo) responden al movimiento contra la mecanización y el desencantamiento de la naturaleza, el cosmos y el ser humano.

Como hemos señalado en otras oportunidades, entendemos al neochamanismo como un conjunto de discursos y prácticas que involucran la integración de técnicas chamánicas (especialmente del continente americano) y psicoterapéuticas por parte de sujetos urbanos occidentales y/o occidentalizados. 
Ha surgido, como otras modalidades "Nueva Era"2 de espiritualidad, en oposición al materialismo y positivismo característicos de la modernidad europea y presenta como idea central la posibilidad de establecer reconexiones con los saberes indígenas. Es resultado en buena medida de la circulación de literatura sobre chamanismo, estados modificados de conciencia (generalmente, aunque no siempre, inducidos por el uso de sustancias psicoactivas) y de la posibilidad de generar nuevas alternativas psicoterapéuticas (Scuro; Rodd, 2015).

El neochamanismo surge en momentos de profunda transformación de paradigmas y epistemologías en diversas áreas del conocimiento, las artes y la política, proceso iniciado a partir de la segunda mitad del siglo XX. Se le caracteriza principalmente por la incorporación de tecnologías provenientes de las poblaciones nativas del continente americano -aunque también existen neochamanismos no americanos. "Lo indígena" pasa a ocupar un lugar hacia donde mirar y aprender para construir modelos diferentes a los hegemónicos desarrollados desde la modernidad/colonialidad (Mignolo, 2007, 2013). Las epistemologías indígenas pasan gradualmente a tener mayor visibilidad y proponer unas miradas otras, interpelantes de las epistemologías dominantes.

Es común observar en ámbitos neochamánicos ciertas seguridades sobre la verdad, que no necesitan de los tipos de argumentación típicas de las formas de conocimiento "positivo". Esta es una encrucijada en el análisis del dispositivo del neochamanismo en tanto espacio de encuentro inter-epistemológico. Por un lado, la modernidad/colonialidad es asociada al desarrollo de una racionalidad específica, donde Kant ocupa el lugar paradigmático de lo que significa

2 En la Nueva Era, aunque se presente como "nueva" convergen una serie de elementos, místicas, filosofías que se remontan al siglo XIX en Europa y que también introduce filosofías orientales. En ese sentido, y haciendo un contrapunto histórico con algunas otras categorías que se han ido introduciendo dentro de las ciencias sociales de la religión, como la famosa "nebulosa mítico esotérica", Viola Teisenhoffer (2008) plantea algunos puntos que permiten ver lo no tan nuevo de la nueva era. Para el caso de la región del Mercosur, el estudio de María Julia Carozzi (1999) da cuenta de estos fenómenos. Por otra parte, el uso de la categoría, un tanto abusado, requiere de mayores problematizaciones que se están llevando adelante. Para una perspectiva de la Nueva Era en América Latina, ver De la Torre, Gutiérrez Zúñiga y Juárez Huet (2013), especialmente, en ese volumen, ver De la Torre (2013), Frigerio (2013). Al mismo tiempo, la categoría fue ingresando a los campos de la salud y la religión en forma simultánea, siendo, de algún modo, la contraparte del auge de la idea de espiritualidad como unión de ambos campos, lo que actualmente está sucediendo y donde el neochamanismo es un ejemplo. Sobre esta aproximación de ambos campos ver el trabajo de Rodrigo Toniol (2017). 
la emancipación del pensamiento, el conocimiento, y en definitiva, la consecuente libertad. Ese pensamiento ilustrado no daría un lugar privilegiado a otras formas posibles de conocimiento de características inmanentes donde la separación sujeto/objeto no cumple la misma función en tanto posibilidad cognitiva, sino que, la subjetivación (y no la objetivación) se convierten en perspectivas privilegiadas para la obtención de conocimiento y de la verdad. A su vez, esa modernidad incluye la posibilidad del desarrollo de paradigmas como el de la modernidad/colonialidad, que, en buena medida, imploran por un pensamiento otro, decolonial. Las antinomias de la modernidad hacen posible la coexistencia de su supuesta antítesis, lo cual nos conduce, en última instancia, a una infinita dialéctica. Cuando Mignolo (2007, p. 80) se refiere al pensamiento de Kant y dice que "el uso de la razón propia sin guía de otros [frase de Kant] implica aceptar la guía de Kant”, está reproduciendo ese juego dialéctico del que no parece haber salida, salvo, quizá, en el pensamiento de frontera: "Cuando me refiero a decolonizar el conocimiento, entonces, lo hago con y contra Kant; de ello se trata el pensamiento crítico de frontera, entendido como decolonización del conocimiento" (Mignolo, 2007, p. 80, énfasis del autor). Y en ese entremedio se desarrolla también el dispositivo del neochamanismo, entre tentativas críticas y producción de colonialidad. El pensamiento de frontera es precisamente un tipo de posibilidad epistemológica que surge del encuentro interepistemológico que se produce al interior del dispositivo del neochamanismo.

Los giros de los años 1960, los aportes de Lévi-Strauss y de Mircea Eliade a la comprensión y mundialización del fenómeno del chamanismo, la contracultura hippie y el psicodelismo, el ecologismo, fueron todos elementos que contribuyeron a conformar un particular conjunto de prácticas y técnicas psico-espirituales que se ensamblaron con facilidad en lo que se denominó como Nueva Era. Las críticas a la modernidad capitalista, colonialista, imperialista, extractivista, racionalista, urbana, verían muchas formas de materializarse. El neochamanismo fue tomando fuerza en esa dirección, trayendo a un primer plano la imagen del indígena americano y sus conocimientos ancestrales, sus técnicas de cura, sus concepciones de la vida, la salud y la enfermedad.

A partir de la década de 1990, con las reemergencias indígenas del continente americano y la circulación mundial de individuos, imágenes, rituales, sustancias y un amplio etcétera, el neochamanismo se iría consolidando cada vez más, alcanzando siempre nuevos horizontes. Así, el neochamanismo 
se constituye como el dispositivo (Deleuze, 1990; Foucault, 1985) que resulta de la aproximación inter-epistemológica que se produce/y es producida por, los principales giros en los paradigmas "occidentales" o "modernos" y que tienen a "lo indígena" como principal argumento, y más específicamente, la circulación de sus técnicas chamánicas tales como el uso de plantas sagradas y otros rituales (Temazkal, Danza del Sol, Ceremonias de Plantas Maestras, etc.). El neochamanismo se expande y consolida por el mundo entre consumidores occidentalizados, en buena medida entre sujetos de sectores sociales más favorecidos, con capital cultural, social y económico que les permite dar rienda suelta a sus inquietudes existenciales, a buscar nuevos horizontes en las experiencias de expansión de la consciencia que permiten las plantas sagradas u otras técnicas neochamánicas.

Estas posibilidades están, en buena medida, vinculadas a los usos de las llamadas plantas sagradas, maestras, de poder, alucinógenas, etc. Algunas de las más reconocidas y relevantes en el desarrollo del neochamanismo en América Latina son la Ayahuasca, Peyote, San Pedro, Tabaco y Hongos. Por razones de espacio no me detendré en la especificidad de las plantas, lo cual he abordado ampliamente en otras oportunidades (Scuro, 2016), pero sí es preciso mencionar que la popularización en el uso de estas sustancias y su llegada a los centros urbanos a partir de la década de 1980 y con mayor notoriedad a partir de los '90 son un factor determinante para la consolidación del neochamanismo tal como lo observamos actualmente. Esto incluso me ha llevado a proponer que el empleo de estas sustancias/drogas/plantas son de alguna forma el "núcleo" del neochamanismo (Scuro, 2016) o del chamanismo urbano que José Guilherme Magnani (1999) ha identificado en San Pablo como parte de los circuitos neo-esotéricos. ${ }^{3}$

A continuación, propongo dejar momentáneamente en suspenso el tema del neochamanismo para dar paso a la descripción de algunos elementos que considero fundamentales para un mejor análisis y comprensión de las "fuentes" que alimentan al neochamanismo.

3 Para una lectura más detenida sobre las especificidades y diferentes modalidades de uso y expansión de la ayahuasca ver, por ejemplo Labate (2004), Labate y Araújo (2009), Labate y Jungaberle (2011), Labate y Bouso (2013), Labate y Cavnar (2014), Labate, Cavnar y Gearin (2017). 


\section{Desde el comienzo}

Desde los trabajos pioneros del antropólogo ruso Sergei Shirokogoroff (18871939) parece haber cierto consenso en relación al origen del término saman, que proviene de las lenguas tungús (Evenki) y pasa al ruso para después pasar al alemán y así llegar al inglés shaman. En lenguas tungús, grupo lingüístico del este siberiano, el término empleado para referirse al "chamán" ha sido registrado como çsaman, sama, saman, shaman, śaman, samman y khamman (Laufer, 1917; Hultkrantz, 1977 apud Winkelman, 2010, p. 65).

Muchos investigadores, luego de los aportes del famoso historiador de las religiones Mircea Eliade (2009), basan sus hipótesis acerca del origen del chamanismo en el trabajo previo de Shirokogoroff (de la década de 1920) de quien toman la mayor cantidad de datos para afirmar la influencia budista de esta práctica en el este siberiano. Eliade (2009), citando a Shirokogoroff, afirma que el fenómeno del chamanismo tungús sería relativamente reciente y que habría sido difundido de Oeste a Este y de Sur a Norte, con fuerte influencia del budismo.

Estos datos continúan enfatizando los orígenes hindúes y budistas del chamanismo. Winkelman, citando a Wayman (1969) muestra la composición de los términos samana-brāhmana, del pali, y śramana-brāhmana, del sánscrito, para designar las funciones religiosas en la antigua India argumentando que el brāhmana representa las formas burocrático políticas e institucionalizadas de la práctica religiosa, mientras que samana o śramana sería reflejo de los aspectos chamánicos, no institucionalizados. De este modo, señala Winkelman (2010, p. 67), Buda es referenciado como un gran śramana, o sea, un gran asceta.

Según el investigador de las religiones Thomas DuBois, la primera vez que se usó el término shaman en alguna descripción de tipo etnográfica habría sido a través del sacerdote ortodoxo Avvakum, quien fuera exiliado en Siberia entre 1653 y 1664. DuBois (2009, p. 20) señala que esa habría sido la primera vez que se utilizó la raíz tungús para describir un tipo de prácticas relacionas con la adivinación. Por otra parte, el antropólogo ruso especialista en chamanismo, Andrei Znamenski (2007), señala como primera referencia de este término los trabajos del explorador alemán Nicolaas Witsen, quien en 1692 utilizó la palabra schaman, también mencionado por DuBois como las primeras referencias 
que utilizaron el término de raíz tungús. Witsen viajó a Rusia entre 1664 y 1665. Sumado a los trabajos de Witsen, Znamenski señala que los expedicionarios alemanes fueron los primeros en diseminar la expresión schamanism entre cierto público "culto" occidental. A partir de ese momento se sucederían varias expediciones a Siberia a lo largo del siglo XVIII. Estas expediciones eran formadas mayormente por naturalistas, zoólogos y botánicos. Las observaciones que se desprendieron de estos estudiosos en relación al chamanismo no fueron adjetivadas de la mejor forma. Respondiendo a una lógica iluminista, las descripciones fueron de carácter escéptico y derogatorio. Los chamanes fueron vistos como enemigos del racionalismo. En definitiva, como muestra Znamenski (2007, p. 9), la conclusión general de la mirada iluminista fue que los "Siberian spiritual practitioners were good for nothing".

Los iluministas se preocuparon por, además de develar la falsedad, conocer los orígenes de esas prácticas en clave difusionista, preocupados con un origen único o múltiple de estas prácticas. Como narra Znamenski, en 1750 el historiador Müller fue de los primeros en sugerir un origen en oriente para el chamanismo, y más específicamente en la India. Por otra parte, sugiere Znamenski (2007, p. 12-13), el poeta, crítico literario y filósofo romántico Friedrich Schlegel fue el primero en trazar el origen del término con raíz en el sánscrito y relacionarlo con samaneans, una expresión para referirse a los monjes budistas en la antigua India.

Si la mayoría de la literatura repite lo que ya se expuso antes sobre las posibilidades de conexión con el término sánscrito sramana o el pali samana, Znamenski (2007, p. 16 argumenta que este deseo de ubicar un lugar de origen para el chamanismo en el clásico Oriente tiene estricta relación con la tradición intelectual del Orientalismo Romántico).

La anterior es una breve síntesis de la historia más ampliamente narrada sobre el uso del término chamanismo, asociado, en una primera instancia, a aquel lejano Oriente. Mientras tanto, el siglo XVIII y su incipiente Historia Natural (consecuente con la publicación, en 1735, de Systema naturae, de Carl Linneo) produciría una relación de conocimiento de la naturaleza acorde a una lógica de observación distante y clasificatoria que iría a imponer un nuevo orden en el imaginado caos de lo desconocido. La recolección de muestras y extracción de ejemplares producirían un ordenado mapa europeo de la "naturaleza" desconocida que "no sólo despojaba a los ejemplares de las relaciones 
orgánicas o ecológicas que mantenían entre sí, sino también de su sitio en las economías, historias y sistemas sociales y simbólicos de otros pueblos" (Pratt, 2011, p. 72) lo que significa que "como manera de pensar interrumpió las redes existentes de relaciones históricas y materiales entre las personas, las plantas y los animales" (Pratt, 2011, p. 72). Pero mas tarde se produciría un giro importante con Humboldt y su reinvención de América cuando se publicó, en 1808, el famoso "Cuadros de la Naturaleza".

De este modo, el siglo XIX en Europa fue el escenario productor de una América muy estrechamente asociada a una naturaleza exuberante, terreno ideal para encontrar allí esos ¿mismos? "chamanes" observados en Oriente. Es que Humboldt "reinventó la América del Sur [...] sobre todo como naturaleza. [...] una naturaleza impresionante, extraordinaria, un espectáculo capaz de sobrecoger la comprensión y el conocimiento humanos" y agrega, "una naturaleza en acción, dotada de fuerzas vitales, muchas de las cuales son invisibles para el ojo humano" (Pratt, 2011 p. 229-230).

Esta naturaleza que Humboldt transmite a Europa reverbera en el idealismo alemán del siglo XIX, el mismo que Kocku von Stuckrad (2002) propone pensar como fuente del reencantamiento de la naturaleza característico del chamanismo occidental moderno. El investigador de las religiones señala al pensamiento de Schelling como base importante del neochamanismo, llamando la atención al énfasis que el neochamanismo coloca en su relación con la naturaleza y que no aparece, según Stuckrad, en las etnografías más antiguas sobre el chamanismo indígena.

La tesis central de Stuckrad (2002, p. 778) es que el concepto de naturaleza que se utiliza en el neochamanismo es un sucesor directo del misticismo occidental y de la filosofía sobre la naturaleza, cuyos ejemplos más relevantes están presentes en la antigüedad, en el renacimiento y en el idealismo alemán del siglo XIX. Para Stuckrad (2002, p. 781), "shamanism is a way -or maybe just a technique- to reach a mystical state of interconnectedness, a spiritual path to unio mystica".

Partiendo de este punto Stuckrad establece el vínculo de este estado chamánico con la Naturphilosophie de Schelling. A diferencia de la filosofía trascendental preocupada con las condiciones de cognición de la naturaleza y de la concepción del sujeto que percibe como unificador de esta exterioridad observada (Kant), Stuckrad interpreta en Schelling una concepción ontológica donde 
la naturaleza es activa en sí misma, un producto de su propia evolución que incluye al sujeto observante. "So it is not that we know nature, but nature is a priori, i.e. every single part in it is determined in advance by the whole or just the idea of nature" (Schelling, 1856, p. 279 apud Stuckrad, 2002, p. 785, énfasis del autor).

El movimiento que coloca Stuckrad, muy centrado en los acontecimientos del norte y pasando por alto las particularidades de los chamanismos americanos, es de un giro que coloca las bases de los discursos del neochamanismo en Europa, y para eso, llama la atención en los siguientes puntos: en primer lugar, la imagen del chamán como un especialista religioso de este otro mundo, de las artes y de la naturaleza, es el producto de la imaginación europea desde el siglo XVIII. En segundo lugar, existen continuidades entre la filosofía de la naturaleza del siglo XIX y el ecologismo contemporáneo (elemento constitutivo del neochamanismo). En tercer lugar, Stuckrad (2002, p. 778) llama la atención respecto a la inseparabilidad de Euro-América como campo discursivo de mutua dependencia, lo que Walter Mignolo $(2007,2013)$ ha denominado como occidentalismo, la idea de América como parte de occidente. El occidentalismo, afirma Mignolo (2013, p. 121), "fue una construcción transatlántica precisamente como la expansión de Europa, el territorio ocupado por los descendientes de Jafet, cuyo nombre ha inscrito su propio destino: 'respiración', 'ampliación'."

\section{Traducción y perspectiva}

Los antropólogos Manuela Carneiro da Cunha, y Eduardo Viveiros de Castro aportan miradas imprescindibles para el estudio del chamanismo. No se trata de unificar sus propuestas, sino de mostrar algunos trazos con los que ha sido caracterizado el chamanismo a partir de sus trabajos empíricos con los chamanismos amazónicos, uno de los epicentros productores de neochamanismo.

Se subrayan en estas miradas el aspecto "periférico" del sujeto chamán en relación al conjunto social al que pertenece. Ser periférico en este sentido, es, contrario a lo que podría suponerse, un lugar privilegiado, ya que es desde allí de donde pueden surgir la perspectiva y las posibilidades de traducción. Veamos. 
De forma clásica se ha definido al chamán como aquel que domina los estados de trance. El viaje chamánico está diseñado como forma de establecer comunicación con las dimensiones de la realidad que no son accesibles en estados ordinarios de conciencia. El chamán intenta aprender la lengua de las diferentes entidades que forman parte de la realidad, para establecer contacto con ellas y aprender así a dominarlas o establecer vínculos, alianzas. Ese estado se alcanza, muchas veces, a través del uso de plantas sagradas. En el caso de varios chamanismos amazónicos, la ayahuasca ocupa un destacado lugar dentro del conjunto de herramientas chamánicas y es esta planta/bebida un motor fundamental en el neochamanismo, dada su explosiva expansión y popularización en ámbitos extra amazónicos y amazónicos. El uso de plantas como la ayahuasca permite el acceso a dimensiones del conocimiento ordinariamente inaccesibles, motivo por el cual se las ha denominado plantas maestras [plant teacher] (Luna, 1984, 1986) e incluso, posteriormente, psicointegradoras (Winkelman, 1996, 2010). Se accede entonces a espacios de la conciencia en los cuales el lenguaje es diferente al que usamos ordinariamente. Se accede a una fuente de conocimiento en la cual es necesario transitar y aprender a navegar para obtener buenos resultados.

En este sentido, el chamán es entendido por Manuela Carneiro da Cunha (1998) como aquél capaz de comprender la lengua universal, lo que, apoyándose en Walter Benjamin, identifica como el traductor. Si Benjamin está preocupado con la incapacidad del lenguaje para rescatar el sentido original (y por lo tanto la traducción es siempre una reinterpretación), de alguna forma sucedería algo similar en una experiencia de expansión de la conciencia a través del uso de plantas u otras técnicas. El lenguaje de las palabras parece ser siempre una profanación de esa experiencia que proviene de otro orden, de otro lenguaje. Y este es el punto que precisamente desarrolla Manuela Carneiro da Cunha (1998), juntando el concepto benjaminiano de traducción con el perspectivismo amerindio de Viveiros de Castro.

El perspectivismo amerindio (Viveiros de Castro, 2002) enfatiza la imposibilidad de pensar las cosmologías amerindias a partir de la distinción naturaleza-cultura. Por el contrario, en vez de existir una continuidad física y una discontinuidad metafísica (característica de "nuestra" cosmología) entre lo humano y la naturaleza, para el perspectivismo propuesto por Viveiros de Castro, lo que existe es una continuidad metafísica (animismo) 
y una discontinuidad física que permite las múltiples perspectivas. En otras palabras, en vez de proponer un multiculturalismo que preconiza la unicidad de la naturaleza observada por una multiplicidad de culturas, el etnólogo propone un multinaturalismo, que enfatiza la existencia en el tiempo mítico de una condición original común entre humanos y animales compartiendo una misma Humanidad que, posteriormente, produciría seres de naturalezas diferentes. Esto equivale a decir que, en vez de una naturaleza vista por diferentes culturas (multiculturalismo), se trata de pensar, para el caso amerindio, de una cultura vista por muchas naturalezas (multinaturalismo).

Viveiros de Castro ejemplifica su teoría sugiriendo que en las cosmologías amerindias, los animales son "ex-humanos" y no los humanos "ex-animales". Partiendo de este origen mítico común, Viveiros de Castro indica que, para los amerindios, existe la posibilidad del perspectivismo, es decir, la posibilidad de adoptar naturalezas diferentes, o sea, subjetividades diferentes (puntos de vista) a través de los cuales es posible adquirir conocimiento.

Si la cosmología euromoderna preconiza un conocimiento basado en la objetivación, los amerindios, al contrario, valorizan la subjetivación (la capacidad de adoptar puntos de vista diferentes), como mecanismo de conocimiento. Quien posee ese poder transespecífico (de adoptar naturalezas diferentes) es, según Viveiros de Castro, el chamán. Aunque las perspectivas deban permanecer separadas "apenas os xamãs podem fazê-las comunicar, e isso sob condições específicas e controladas" (Viveiros de Castro, 2002, p. 378). O en palabras de Luis Eduardo Luna: "No xamanismo do Alto Amazonas, com freqüência esta transformação se leva a cabo mediante alguma planta psicotrópica, sendo a ayahuasca, talvez, a de maior difusão e importância". Y agrega el antropólogo que la ayahuasca "facilitaria a percepção multissensorial de 'energias' intimamente ligadas com objetos do mundo natural, e que seriam interpretadas como seres inteligentes" (Luna, 2009, p. 195).

Esta es precisamente la cualidad del chamán en la lectura que hace Carneiro da Cunha cuando se refiere a estos sujetos como aquellos que permiten la traducción, y por lo tanto, la totalización de los puntos de vista singulares, la resonancia, la armonía (Carneiro da Cunha, 1998, p. 17).

Los aportes de Carneiro da Cunha y de Viveiros de Castro ayudan a relativizar en alguna medida el eurocentrismo de Stuckrad, pues, aunque Michael Taussig (2012) y Kocku von Stuckrad (2002) estén correctos en pensar 
el chamanismo en términos de proyecciones eurocéntricas, no podemos simplemente dejar de lado el trabajo etnológico de Viveiros de Castro o Carneiro da Cunha o negar, como el mismo Taussig advierte, que de hecho existen conocimientos nativos productores de los más variados efectos. Puede existir proyección e invención en la figura del chamán y del chamanismo, eso es un hecho, pero no parece ser una proyección o una invención de la filosofía europea el conocimiento que algunos sujetos poseen. Estos sujetos pueden estar en mayor o menor contacto con los diferentes intereses que generan redes de circulación de sus conocimientos, teniendo mayor o menor grado de transformación o adecuación a los deseos de quienes ponen dichos conocimientos en circulación. En qué medida emergen las proyecciones o los contenidos reales de conocimientos nativos es lo que va transformando al chamanismo a lo largo de la segunda mitad del siglo XX, convirtiéndolo en neochamanismo y esa es precisamente la trama del neochamanismo en tanto dispositivo, como he intentado desarrollarlo en el marco de una modernidad/colonialidad (Scuro, 2016), o mejor, de una (pos)modernidad/(pos)colonialidad donde la perspectiva de Taussig se vuelve imprescindible. Desde el punto de vista colonial, afirma el antropólogo australiano "el ser no civilizado y parte de lo salvaje significaba que los indios eran poseedores de poderes sobrenaturales" (Taussig, 2012, p. 15).

Dado el poder de esta ideología, el colonizador [...] está de hecho curándose a sí mismo con el poder místico atribuido al 'primitivo'. Esto no quiere decir que los milenios de experiencia indígena en sembrar plantas medicinales y hacer rituales curativos no sean intensamente poderosos en sí mismos. Sí quiere decir sin embargo, que mucho de lo que se toma como poder indio derivado del yagé [ayahuasca], es también una proyección de una fantasía europea sobre el indio. (Taussig, 2012, p. 15).

\section{De enfermo a curador}

Durante la primera mitad del siglo pasado predominó en los estudios sobre chamanismo una fuerte influencia de las incipientes teorías psicológicas de la época. Los expedicionarios de fines del siglo XIX e inicios del XX aportaban una complejidad interesante de posibilidades de comportamiento humano 
que pensadores europeos observaron a través de los lentes del psicoanálisis y, en buena medida, "patologizaron" el comportamiento chamánico. Fue común durante esa primera mitad del siglo XX una suerte de relación de desconfianza con las prácticas chamánicas, en el entendido de que aquellos que las llevaban adelante eran vistos como sujetos patológicos.

La psicopatologización del chamán se basó en buena medida en los comportamientos de los siberianos, lo que se identificaría como "histeria ártica", sobre la cual se produjeron varias interpretaciones, muchas veces centradas en los aspectos geográficos, las características climáticas del ambiente siberiano como productor de esas patologías. Por otra parte, Znamenski (2007, p. 87) señala que Shirokogoroff se vio fuertemente entusiasmado por la propuesta de la antropóloga Marie Antoinette Czaplicka, quien llamó la atención de que los comportamientos observados en contexto siberiano y llamados de histeria ártica, explicados a través de las relaciones con el ambiente, se encontraban también en otras regiones del mundo, como los ambientes tropicales. Esto interpelaba las suposiciones de la época. La antropóloga polaca sugirió entonces, como narra Znamenski (2007, p. 87): "before labeling that unusual behavior as pathology, it would be better to ask the indigenous people themselves what they had to say about their own hysterical fits". Y esto es precisamente lo que fue a hacer Shirokogoroff, comenzando a desmentir las asociaciones europeas con aspectos ecológicos o económicos como explicaciones de la histeria. Lo que para los europeos parecía anormal, era un comportamiento normal en el contexto de la cultura indígena. Shirokogoroff "concluded that arctic hysteria had nothing to do with mental illness" (Znamenski, 2007, p. 88).

Shirokogoroff parece ser un buen antecedente que sienta las bases para que, a partir de las perspectivas teórico-analíticas de mitad del siglo XX, representadas en las famosas obras de Claude Lévi-Strauss ("La eficacia simbólica" y "El hechicero y su magia" de 1949) y de Mircea Eliade ("Las técnicas arcaicas del éxtasis", de 1951), comience a producirse un giro importante en las ideas en torno al chamanismo. El proceso consistió en el gradual abandono de las ideas del chamán enfermo o charlatán para pasar a comprenderlo en términos "psico y socio integradores", que como explica Ismael Apud (2013, p. 16-17), "trae consigo una nueva analogía, la del chamán y el psicoterapeuta, de fundamental importancia para la adaptación de la práctica chamánica a contextos urbanos en la sociedad occidental". En otras palabras, "Eliade must be adressed 
as the major 'turntable' between nineteenh-century intellectual discourse and the popular appropriation of shamanism in the second half of the twentieh century" (Stuckrad, 2002, p. 774).

El historiador rumano Mircea Eliade (1907-1986) “mundializa” el fenómeno del chamanismo, más allá de sus características siberianas. Eliade busca la especificidad del chamanismo y expande la categoría a un amplio conjunto de prácticas que compartirían las mismas características. Para Eliade, administrar el trance extático es la especificidad del chamanismo y explica que "no se puede considerar a un extático cualquiera como chamán; éste es el especialista de un trance durante el cual su alma, se cree, abandona el cuerpo para emprender ascensiones al Cielo o descendimientos al Infierno" (Eliade, 2009, p. 23).

La perspectiva fenomenológica de Eliade, junto con su metodología histórica y su método comparativo lo hacen buscar en el chamanismo formas arcaicas, en el sentido de ser unas formas primarias de espiritualidad, lo que en definitiva permite a esos sujetos mantener un contacto directo con la divinidad o lo sagrado. Lo que interesa para el desarrollo del neochamanismo es que Eliade, más allá de aceptar o no las posibles psicopatologías del chamán, introduce la idea de cura. A Eliade no le interesa tanto si el chamán es o no un enfermo mental, lo cual relativiza, sino que, en caso de serlo, es aquél que ha curado a otros y se ha curado a si mismo. En todo caso, Eliade no ve el hecho de la enfermedad como un problema sino precisamente como la posibilidad de un sujeto de ser "escogido" para iniciar un camino hacia la condición de chamán.

La combinación de su mirada fenomenológica con el método comparativo es lo que lleva a Eliade a buscar universales dentro de la experiencia místicoreligiosa, como el vuelo mágico dentro del chamanismo. La idea de ascender a un "cielo" y descender a un "infierno", o la idea de que existe un axis mundi que une los tres niveles del universo chamánico (cielo, tierra, infierno) remiten a una búsqueda de arquetipos. De hecho, como señala Znamenski (2007, p. 173), Eliade fue muy cercano a Jung en lo que respecta a las búsquedas de simbolismos religiosos transculturales y el hallazgo de arquetipos religiosos. En definitiva, Eliade está buscando la "esencia" del chamanismo, o de características mínimas compartidas que remitan a lo mismo.

Eliade mundializa la experiencia extática como tal, no sólo en sentido geográfico sino también a través del tiempo, hasta alcanzar una suerte de unión mística primordial que vendría de los orígenes mismos del tiempo y afirma, 
"La experiencia extática es un 'fenómeno originario", y la considera "constitutiva de la condición humana" (Eliade, 2009, p. 384).

Un componente específico del trabajo de Eliade que será de gran eficacia dentro del neochamanismo, es la idea de que esta reconexión con el tiempo mítico originario es una de las características que el mundo moderno habría perdido. En "El chamanismo y las técnicas arcaicas del éxtasis" Mircea Eliade resume su mirada "benevolente" hacia la figura del chamán, entendiendo a éste como un protector de las fuerzas del mal, un curador, un "defensor de la integridad física de la comunidad" (Eliade, 2009, p. 387), un guerrero, un miembro de la comunidad capaz de ver lo que está oculto a los demás.

Como señala Znamenski, Eliade tuvo una lectura de la técnica del éxtasis como una vía de retorno al tiempo mítico originario del que la humanidad se habría ido separando. En este punto, se intuye una mirada a las sociedades "chamánicas" como privilegiadas, a diferencia de las "civilizaciones" y las religiones organizadas, las que representarían un paso más en este proceso de separación respecto al estado mítico originario. En la mirada de Eliade, la sociedad moderna no habría sido capaz de producir agentes humanos que, como los chamanes, pudieran retornar espiritualmente a los sujetos al paraíso perdido e incluso apunta que muchos problemas contemporáneos de la tradición occidental están relacionados a esta marginalización de lo espiritual y en su endiosamiento de la ciencia y la tecnología. Eliade, a tono con el movimiento contracultural de la década de 1960, llamaba la atención a europeos y estadounidenses respecto a la importancia que tenía mirar hacia las sociedades no occidentales para poder ver el mundo a través del mito y lo espiritual, lo que llevaría a las personas nuevamente a su estado de armonía original (Znamenski, 2007).

Estos son elementos que hacen que la crítica Alice Beck Kehoe (2000) sostenga que la visión de Eliade representa una versión moderna romántica del primitivismo.

Alice Beck Kehoe, fuerte crítica de Eliade, reivindica el uso del término chamanismo para el caso exclusivo de Siberia (en términos estrictos Eliade también), enfatizando las diferencias que existen entre todos esos otros a los que se refiere Eliade. Según Kehoe, el entrenamiento académico de Eliade dentro de la tradición europea, que entiende cierto tipo de conocimiento como más elevado que aquel de las experiencias prosaicas de un Otro imaginado homogéneo, 
hicieron que Eliade adoptase una postura racista en su visión del chamanismo como universal para toda aquella expresión religiosa no occidental basado en un supuesto éxtasis que la autora relativiza (Kehoe, 2000).

Lo que sucedió con el término chamán, señala Kehoe, fue que Eliade consiguió modernizarlo, y esto hizo que antropólogos como Peter Furst o Gerardo Reichel-Dolmatoff, al observar las prácticas de los nativos que estudiaban (huicholes en México y tukano en Colombia respectivamente), "exclaimed 'Shaman!' when they saw American Indian ritual leaders appear to slide into ecstatic introspection" (Kehoe, 2000, p. 44).

$\mathrm{Y}$ esos "chamanes" contaban entonces con la suerte de un importante giro en las interpretaciones sobre sus prácticas y sus técnicas. Si Mircea Eliade fue de algún modo "benévolo" con el chamanismo y lo "mundializó", debemos también a Lévi-Strauss buena parte de la responsabilidad por establecer nuevas analogías posibles entre el chamán y, por ejemplo, el psicoterapeuta. Ambos, sostiene Lévi-Strauss utilizando un término prestado del psicoanálisis, producen la abreacción, es decir, tienen la capacidad de hacer revivir intensamente una situación traumática que produjo un trastorno, pudiendo de este modo superarlo (Lévi-Strauss, 1995).

En el complejo chamanístico identificado por el etnólogo francés intervienen tres elementos diferenciales y complementarios para que la experiencia sea exitosa. En primer lugar, el hechicero/mago/chamán debe creer en la eficacia de sus propias técnicas. Por otra parte, el paciente debe creer en el poder del chamán. Finalmente, pero no menos importante sino, al contrario, fundamental, debe existir la "complicidad" del público, siendo este el que efectivamente, en la mirada del estructuralista, hace posible la eficacia de las relaciones entre chamán y paciente, al punto de establecer su clásica máxima que afirma que el sujeto no se convierte en un poderoso chamán por curar a sus pacientes, sino que cura a sus pacientes por haberse convertido en un poderoso chamán (LéviStrauss, 1995, p. 207).

Veamos de qué forma podemos comprender este "complejo chamanístico" identificado por Lévi-Strauss en términos de los sistemas de cuidados de salud propuestos por el psiquiatra estadounidense Arthur Kleinman (1978, 1979). Según Kleinman, los sistemas de cuidados de la salud están conformados por tres áreas: la popular, la profesional y la folk. El área popular está formada por los vínculos del individuo con su familia y red social 
donde son tomadas decisiones en torno a la enfermedad y sus cuidados. El ámbito folk está comprendido por especialistas no profesionales, un área no burocrática. Según Kleinman, estas dos dimensiones son las que forman los sistemas de cura indígenas.

En el modelo de Kleinman, a su vez, se hace una distinción entre disease e illness. Disease podría traducirse como enfermedad, es decir, el mal funcionamiento de algún proceso biológico o psicológico. Illness, en cambio, se refiere a la experiencia de la enfermedad y a la reacción social ante esta. En sus palabras, "Illness is the way the sick person, his family, and his social network perceive, label, explain, valuate, and respond to disease" (Kleinman, 1978, p. 88). Siguiendo esta lógica es factible la posibilidad de experimentar illness sin disease y viceversa. Con estas bases Kleinman señala que el modelo explicativo del sistema médico de la biomedicina estructura su visión de la realidad clínica donde la enfermedad es situada dentro del cuerpo de la persona enferma. Siendo así, el médico busca el tratamiento de ese fragmento. De forma diferente, otros sistemas localizan el problema no necesariamente dentro del cuerpo del paciente, y por lo tanto, el tratamiento puede involucrar más que únicamente el cuerpo del paciente. Kleinman sostiene que una de las razones por las cuales no desaparecen los curadores indígenas es porque estos trabajan más con los aspectos de la experiencia (illness) que con la enfermedad (disease).

Haciendo un juego entre la diferenciación establecida por Arthur Kleinman entre disease e illness, la antropóloga Jean Langdon distingue entre cura y experiencia de cura. Su pregunta apunta hacia la cura en sí misma, a ¿qué se entiende por curar? Es por eso que distingue entre "cura" y "experiencia de cura". La primera, dice Langdon (2013), trata de los aspectos sintomáticos, mientras que la última tiene un sentido de integralidad y no necesariamente está vinculada a la cura. La experiencia de cura de Langdon se asemeja a la idea de sanación, ${ }^{4}$ tan común en los ámbitos neochamánicos. Incluso, el énfasis de Langdon está colocado en la denuncia que hace de los modelos basados en el compartir un conjunto de significados simbólicos (como propone Lévi-Strauss),

4 Una distinción entre cura y sanación la plantea el antropólogo y terapeuta catalán Josep María Fericgla (2013, p. 426) cuando dice, "sanación es el proceso de recuperar la salud y el bienestar como estado global y armonioso del ser, curación es el proceso de curar una patología concreta. En el mejor de los casos, los chamanes sanan y los médicos curan". 
mostrando que estos modelos son insuficientes para explicar la eficacia de las técnicas chamánicas en las religiones y las prácticas de la Nueva Era, donde este simbolismo común no está, según Langdon, presente.

\section{El uso de las plantas maestras es la más paradigmática y eficaz práctica seductora y expansionista del neochamanismo}

Luis Eduardo Luna $(1984,1986)$ ha introducido, a través de su trabajo con los vegetalistas peruanos, la idea que estos utilizan para referirse a determinadas plantas como plantas maestras o doctores y se refiere a ellas como "plant teachers". Luna presenta esta idea que los vegetalistas peruanos (tradición y actores altamente relevantes para el desarrollo del neochamanismo) utilizan para referirse a los modos a través de los cuales adquieren el conocimiento necesario para curar y utilizar las plantas. Este aprendizaje, señala Luna, se realiza a través de las plantas maestras, plantas doctoras, que tienen espíritu y el poder de enseñar (a aquel que realiza de forma adecuada la dieta correspondiente para utilizarlas) las formas de trabajar con ellas para diversos fines. Los vegetalistas son aquellos sujetos que han aprendido, a través del uso de plantas, diferentes posibilidades de cura.

Para ser vegetalista (digamos, "chamán") suele observarse un mecanismo hereditario, el sujeto chamán accede a esa condición de forma única en su comunidad. En el chamanismo clásico no todos pueden ser chamán. Y este es un punto importante en el neochamanismo, que lo separa de lo que podríamos denominar como "chamanismos clásicos". En el neochamanismo, y quizá sea esta una de las más importantes características que lo distinguen de sus fuentes tradicionales, es que todos y cada uno pueden llegar a ser chamanes. $O$ sea, se trata de un mecanismo de búsqueda y desarrollo del "chamán interior" que habita en cada uno y que se puede "despertar" o "desarrollar" por medio de los ámbitos neochamánicos.

En la actualidad, las múltiples formas de uso y apropiaciones de la ayahuasca, por ejemplo, genera diferentes incertidumbres en el campo y surgen tentativas de regulación de las prácticas asociadas a esta planta. Por ejemplo, en la II World Ayahuasca Conference desarrollada en la ciudad de Rio Branco (Acre) 
en octubre de 2016, se hizo explícito el enfrentamiento entre diferentes lecturas de la ayahuasca y sus usos. Las religiones ayahuasqueras brasileras, los indígenas, los científicos, cada uno de esos campos a su vez con enormes diferencias internas, y otros agentes, pusieron de manifiesto la dificultad de establecer acuerdos o pautas de acción conjuntas. Disputas por legitimidades, usos adecuados e indebidos, patrimonios, licencias, conservación y un amplio etcétera fueron y son algunos de los puntos centrales en los que se desarrollan las principales tensiones del campo ayahuasquero mundial. Esto incluye, por cierto, a los neochamanes y grupos neochamánicos, espirituales, científicos, etc., de todo el mundo. Entre esta complejidad y heterogeneidad de apropiaciones posibles, el campo se desarrolla con nuevas discursividades que pueden avanzar hacia diferentes espacios de legitimación. Por ejemplo, el hecho de ser religiones es lo que ha dado el principal argumento defensivo legal a las denominadas religiones ayahuasqueras brasileras, tanto dentro de Brasil como fuera, para legitimar sus prácticas y acceder a las garantías legales mínimas que aseguren el correcto desempeño de sus prácticas. Alberto Groisman (2013) plantea un buen ejemplo de ello.

En ámbitos que no necesariamente eligen asociarse a una imagen religiosa, sino que apuntan a construir discursos legitimantes en torno a las potencialidades de cura que traen las técnicas neochamánicas o el uso de ayahuasca u otras sustancias, se acude también, generalmente, a la legitimación por la vía tradicional. Es decir, se recurre tanto a un discurso médico científico como al hecho de permanecer (el grupo neochamánico, su líder, etc.) dentro de un "linaje ancestral" específico. Reproducir las prácticas, estar autorizado por un "verdadero chamán", mantener un profundo intercambio de aprendizaje con las "fuentes originales" es entonces un mecanismo de legitimación en muchos ámbitos neochamánicos.

Sin embargo, también estamos asistiendo a un escenario donde esos discursos se están transformando fuertemente. Por ejemplo, un importante grupo ayahuasquero que se ha ido desarrollando principalmente en Europa, denominado Ayahuasca Internacional, muestra una imagen pública claramente "empresarial" y descontextualizada de los aspectos chamánicos originales. Desde este lugar, no se tiene reparos en mostrar el componente empresarial y "no espiritual", "no religioso", "no tradicional" de sus prácticas. Por el contrario, la presentación pública es justamente la de poder adaptar y transformar 
todos estos componentes a las necesidades y características de cada lugar al que llega esta organización. Frases como "nuestra empresa es una familia y amamos la familia" muestran un ingenioso arreglo de los sentidos de "empresa" y "familia" que resultan muy interesantes en el campo neochamánico ya que el neochamanismo tendría en principio un discurso de alguna forma "anti" convencional, "anti" capitalista.

Estos elementos nos conducen a pensar en los componentes "carismáticos" en las estrategias de grupos que promueven el empleo de ayahuasca como herramienta terapéutica. En el caso de Ayahuasca Internacional, por ejemplo, en ocasión de una presentación pública que la organización realizó en la ciudad de Montevideo en Mayo de 2016, se pudo observar una reiterada mención a los beneficios del empleo de ayahuasca. También se enfatizó el hecho de no ser esta organización una institución religiosa. Además, se recurrió en varias ocasiones a las experiencias pasadas de su líder, Alberto Varela, quien estuvo preso varios meses en España por causas vinculadas al uso de ayahuasca. El discurso de Varela resultó una interesante y hábil mezcla de componentes de "rebeldía" (haciendo alusión permanente a su condición de perseguido, preso, etc., lo cual es un componente discursivo siempre seductor) mezclado con eficacia terapéutica que no necesariamente está vinculada a un componente religioso o espiritual, sino psicoterapéutico, y haciendo explícito (y esto sí es una novedad) el carácter empresarial de su organización.

En la presentación pública de Ayahuasca Internacional en el hotel Sheraton de Montevideo fueron también proyectados algunos videos con historias de participantes que relatan haberse curado de varias dolencias psico-físico-emocionales a través de la participación en los retiros de Ayahuasca Internacional. La narrativa de los videos producía rápidamente un efecto emocional fuerte en los participantes de la charla, en un gran salón de lujo (de hecho, como el mismo Varela comentó en algún momento, el "más caro de la ciudad"). Lo que pudo observarse en esa ocasión, e intentando retomar los cabos abiertos hasta aquí, no distó demasiado de lo que se puede observar, por ejemplo, en ocasiones de cura/descarga en ámbitos neopentecostales, donde se acude fácilmente a la conmoción de los participantes y a generar la convicción de que así como los ejemplos que se muestran son exitosos del punto de vista de la cura de algo, quien asiste también puede curarse fácilmente con las técnicas que se ofrecen en ese momento. 
Varela expuso en esa ocasión (y con esto cierro el tema del potencial de las plantas maestras y la característica "democratizante" del neochamanismo en el sentido de que la capacidad de cura están presentes en cada uno) que "a esto nos dedicamos, a que te des cuenta de que el poder lo tienes tu".

La intención de traer este ejemplo aquí es mostrar alguna de las direcciones en las que se desarrolla el segmento religioso-terapéutico-espiritual vinculado al uso de plantas maestras. Si en la II World Ayahuasca Conference predominó en cierto sentido un énfasis en la necesidad de respetar los usos tradicionales de la ayahuasca y si, en buena medida, ámbitos neochamánicos recurren a las formas "tradicionales" de empleo como mecanismo legitimante, vemos, en el caso de Ayahuasca Internacional, que la expansión de los usos de la ayahuasca muestra nuevas facetas que implican desafíos analíticos, pues, en buena medida, en la presentación pública de esa organización se enfatizó en el hecho de "descontextualizar la ayahuasca de su contexto amazónico, chamánico", tal como expresó su líder, Alberto Varela.

En la misma presentación, Varela, hablando sobre sí mismo dijo: "realmente no tengo idea de quién soy", y continuó, "tengo seis hijos, pero no soy padre"; "tengo cinco empresas, pero no soy empresario"; "tengo el sexo masculino, pero no soy hombre"; "nací en Argentina, pero no soy argentino".

Evidentemente se trata de un discurso que apunta a la búsqueda de una verdad "más profunda" que aquella cotidiana "de la ilusión", que, desde una ontología chamánica, no serían más que superficies e identificaciones que no darían cuenta de la Verdad oculta. Esa Verdad oculta a la que sería posible acceder a través del uso de plantas como la ayahuasca.

Es muy repetida la caracterización del neochamanismo y de la Nueva Era en general como espacios terapéutico-espirituales que promueven el "autoconocimiento", "la búsqueda interior", el "desarrollo individual", etc. Sin duda, las palabras de Varela podrían apuntar en esta dirección, en el sentido de hacer explícito el camino de "deconstrucción" de las capas de identificaciones con las que nos vamos socializando en nuestras trayectorias vitales. Hasta ahí nada nuevo. Ahora bien, ¿en qué medida este tipo de discursos pueden ser solidarios con los componentes, por ejemplo, "chamánicos tradicionales" o "emancipatorios", proyectos en los cuales parece haber mayor grado de autopercepción de la posición de sujeto, del lugar que se ocupa en el entramado social, de las responsabilidades que se atribuyen a esos sujetos 
comprometidos con la transformación material de sus comunidades? ¿Qué queda de "chamánico" en Ayahuasca Internacional? ¿Cómo operan los componentes emancipatorios característicos de los proyectos transformadores que apuntan hacia la naturaleza (social) exterior en un ámbito que se presenta como posibilidad para desarrollar ese camino pero con producción de subjetividades que apuntan a perder los parámetros de identificación y de posicionamiento social-individual?

\section{Consideraciones finales}

El neochamanismo es un dispositivo alimentado por varias fuentes que, si bien surge en un contexto de contracultura interpelante de paradigmas euro-estadounidenses-modernos hegemónicos, produciendo subjetividades que pretenden relativizar las relaciones de saber-poder, es consecuente y producto del mismo proyecto de modernidad/colonialidad en una relación, grados y formas que es necesario continuar profundizando.

Ese es un nudo gordiano en el análisis del neochamanismo; descubrir las articulaciones existentes como formaciones discursivas emergentes en el neochamanismo en cuanto potencial transformador, al mismo tiempo en que su condición de posibilidad, es un sistema social abierto con formaciones hegemónicas, que necesitan, como lo señalan Ernesto Laclau y Chantal Mouffe (2010), de unas relaciones de fuerzas que aseguren prácticas articulatorias antagónicas, siendo, entonces, parte de una inacabable dialéctica. Si bien el neochamanismo en cuanto dispositivo puede beber de su mitología contracultural, acaba siendo, en igual o mayor medida, un proceso de "acomodación", de adaptaciones y encajes que se amalgaman unos a otros transformando la propia mitología de origen permanentemente y, al mismo tiempo, viviéndola.

En el neochamanismo convergen discursos e imaginarios provenientes de genealogías diferentes, tanto de raíces, digamos, "cristiano/modernas" como aquellos que, por otra parte, lo harían desde las propias epistemologías nativas. Sucede que:

Los saberes subordinados y subalternizados por quienes creyeron en la superioridad de la teología, de la filosofía, de la ciencia y de sus principios y métodos, 
están volviendo, después de cinco siglos de supervivencia y resistencia, a indicar las vías de futuros posibles más allá de las vías agotadas y las posibilidades que ofrecen el pensamiento moderno, y sus críticos, desde el Renacimiento al posmodernismo. (Mignolo, 2013, p. 22).

Si bien esto parecería notorio en los ámbitos neochamánicos, no resulta sencilla la tarea de "rastrear" componentes discursivos tan claramente asociables a "unos" u otros" en esa imaginada dualidad. Se trata, a mi modo de ver, de comprender el potencial emancipatorio real que el dispositivo del neochamanismo pueda poner en práctica, pero intentando escapar a las dicotomías que plantean, tanto el paradigma de la modernidad/colonialidad, como los discursos más radicales dentro del neochamanismo, que reducen rápidamente el pensamiento a una dualidad donde "lo indígena" es "ancestral" y "bueno" y lo europeo es moderno/colonial, esquema de razonamiento mucha veces característico de los ámbitos de la Nueva Era. Los sujetos que mayoritariamente conforman las redes del neochamanismo, provienen de ambientes donde han sido hegemónicos los modos de pensar que caracterizarían a la modernidad/ colonialidad. Por otra parte, a ese dispositivo lo conforman también muchos sujetos pertenecientes al conjunto de los que Mignolo (2013, p. 20) identifica como habiendo sido subordinados y subalternizados, que "han vivido o aprendido en el cuerpo el trauma [...] el ninguneo que los valores de progreso han impuesto a la mayoría de habitantes del planeta, que, en este momento, tienen que 'reaprender a ser'."

El neochamanismo permite esos encuentros. El mismo dispositivo da la posibilidad del intercambio, hace posible, vehiculiza de algún modo una vía de salida de esos saberes subalternados que encuentran en el dispositivo del neochamanismo su posibilidad de alcanzar nuevos sujetos. Por otra parte, quienes de algún modo "reciben" y transforman esas prácticas y saberes se enfrentan a unas disyuntivas que van desde la posibilidad de plantearse giros más o menos radicales en las trayectorias individuales, en el sentido de optar por nuevas formas de vida, como sucede, hasta aprovechar las potencialidades comerciales que este conjunto de nuevas emergencias de imaginarios permite -0 ambas posibilidades juntas.

A través del dispositivo del neochamanismo, se articula la posibilidad de que una serie de otras posibilidades de relacionamiento -por ejemplo, 
con el conocimiento o la naturaleza- alcancen a ciertos espacios del conjunto social -aquel habitado por quienes reproducen, ponen en práctica, las formas dominantes de relacionamiento con esos ámbitos.

En este sentido, la mirada crítica de Alhena Caicedo sobre los discursos y prácticas que se ponen en circulación en el neochamanismo, entre "alternativas/reproductoras" se hace imprescindible. La antropóloga colombiana identifica las tensiones entre las propuestas neochamánicas en cuanto discursos contra-hegemónicos en el marco de una modernidad/colonialidad que precisamente, produce ese neochamanismo (Caicedo, 2007). Ese es el punto, situando al neochamanismo como dispositivo entremedio, productor de subjetividades que puedan ver en la intención contra-hegemónica una alternativa, al mismo tiempo, sujetadas por los mecanismos de la modernidad/ colonialidad.

Quienes participan de estos ámbitos buscan una reconexión con sus pasados, con sus presentes, con la naturaleza. Buscan sanar lo que no pueden sanar en los ámbitos más convencionales de cura y espiritualidad. Proyectan un poder mágico de cura en la imagen de un idealizado indígena sabio, ancestral y en armonía con la naturaleza. Prefieren ir un poco más despacio, quizá alimentarse de forma saludable, interpelar las lógicas dominantes de vida urbana, estar más cerca de la naturaleza. El conocimiento de sí mismos los moviliza fuertemente. Son sujetos sensibles que valoran un abrazo, una puesta de sol, o ver la lluvia caer sobre un pétalo. Quieren un mundo diferente, los motiva un Gran Espíritu que los invita a relacionarse con la totalidad, el amor, la paz y la armonía. En algunos casos emergen posibilidades comunitarias, quieren una revolución pacífica, espiritual, que comienza con la transformación individual. Quieren acallar un poco sus egos, aunque a veces estos se les engrandecen un poco más. Quieren un mundo diferente, aunque a veces, quizá con buena voluntad y algo de ingenuidad, son piezas perfectas para que el mundo siga girando tal como lo ha venido haciendo en los últimos tiempos y de este modo, el neochamanismo se constituye como estrategia ampliamente solidaria con lógicas de consumo, turismo y exotización de alteridades características de la etapa actual de desarrollo del capitalismo. 


\section{Referencias}

APUD, I. Ceremonias de ayahuasca: entre un centro holístico uruguayo y el curanderismo amazónico peruano. 2013. Tesis (Maestría en Metodología de la Investigación Científica)-Universidad Nacional de Lanús, Montevideo, 2013.

ATKINSON, J. Shamanism today. Annual Review of Anthropology, Palo Alto, n. 21, p. 307-330, 1992.

CAICEDO, A. Neochamanismo y modernidad. Lecturas sobre la emancipación. Nómadas, Bogotá, n. 26, p, 114-127, 2007.

CARNEIRO DA CUNHA, M. Pontos de vista sobre a floresta amazônica. Mana, Rio de Janeiro, v. 4, n. 1, p. 7-22, 1998.

CAROZZI, M. J. (Org.). A Nova Era no Mercosul. Petrópolis: Vozes, 1999.

DE LA TORRE, R. Religiosidades indo y afroamericanas y circuitos de espiritualidad new age. In: DE LA TORRE, R.; GUTIÉRREZ ZÚÑIGA, C.; JUÁREZ HUET, N. (Coord.). Variaciones y apropiaciones latinoamericanas del new age. México: Publicaciones de la Casa Chata, 2013. p. 27-46.

DE LA TORRE, R.; GUTIÉRREZ ZÚÑIGA, C.; JUÁREZ HUET, N. (Coord.). Variaciones y apropiaciones latinoamericanas del new age. México: Publicaciones de la Casa Chata, 2013.

DELEUZE, G. ¿Qué es un dispositivo?. In: DELEUZE, G. et al. Michel Foucault filósofo. Barcelona: Gedisa, 1990. p. 155-163.

DUBOIS, T. An introduction to shamanism. Cambridge: Cambridge University Press, 2009.

ELIADE, M. El chamanismo y las técnicas arcaicas del éxtasis. México: FCE, 2009.

FERICGLA, J. M. Cambios en el perfil de valores tras una experiencia con ayahuasca. In: LABATE, B.; BOUSO, J. C. (Ed.). Ayahuasca y salud. Barcelona: La liebre de marzo, 2013. p. 424-432.

FOUCAULT, M. El juego de Michel Foucault. In: FOUCAULT, M. Saber y verdad. Madrid: La piqueta, 1985. p. 127-162.

FRIGERIO, A. Lógicas y límites de la apropiación new age: donde se detiene el sincretismo. In: DE LA TORRE, R.; GUTIÉRREZ ZÚÑIGA, C.; JUÁREZ HUET, N. (Coord.). Variaciones y apropiaciones latinoamericanas del new age. México: Publicaciones de la Casa Chata, 2013. p. 47-70.

GROISMAN, A. Salud, riesgo y uso religioso en disputas por el estatus legal del uso de ayahuasca: implicaciones y desenlaces de procesos judiciales en los Estados Unidos. In: LABATE, B.; BOUSO, J. C. (Ed.). Ayahuasca y salud. Barcelona: La liebre de marzo, 2013. p. 245-266. 
KEHOE, A. Shamans and religion: an anthropological exploration in critical thinking. Illinois: Waveland, 2000.

KLEINMAN, A. Concepts and a model for the comparison of medical systems as cultural systems. Social Science and Medicine, Oxford, n. 12, p. 85-93, 1978.

KLEINMAN, A. Why do indigenous practicioners successfully heal?. Social Science and Medicine, Oxford, n. 13b, p. 7-26, 1979.

LABATE, B. A reinvenção do uso da ayahuasca nos centros urbanos. Campinas: Mercado de Letras, 2004.

LABATE, B.; ARAÚJO, W. (Org.). O uso ritual da ayahuasca. Campinas: Mercado de Letras, 2009.

LABATE, B.; BOUSO, J. C. (Ed.). Ayahuasca y salud. Barcelona: La liebre de marzo, 2013.

LABATE, B.; CAVNAR, C. (Ed.). Ayahuasca shamanism in the Amazon and beyond. New York: Oxford University Press, 2014.

LABATE, B.; CAVNAR, C.; GEARIN, A. (Ed.). The world ayahuasca diaspora: reinventions and controversies. London: Routledge, 2017.

LABATE, B.; JUNGABERLE, H. (Ed.). The internationalization of ayahausca. Zurich: Lit Verlag, 2011.

LACLAU, E.; MOUFFE, C. Hegemonía y estrategia socialista. Buenos Aires: Fondo de Cultura Económica, 2010.

LANGDON, J. La eficacia simbólica de los rituales: del ritual a la "performance". In: LABATE, B.; BOUSO, J. C. (Ed.). Ayahuasca y salud. Barcelona: La liebre de marzo, 2013. p. 88-119.

LÉVI-STRAUSS, C. Antropología estructural. Barcelona: Paidós, 1995.

LUNA, L. E. The concept of plants as teachers among four mestizo shamans of Iquitos, Northeastern Peru. The Journal of Ethnopharmacology, n. 1, p. 135-156, 1984.

LUNA, L. E. Vegetalismo: shamanism among the mestizo population of the Peruvian Amazon. 1986. Tesis (Doctorado en Estudios Comparados Sobre Religión)-University of Stockholm, Stockholm, 1986.

LUNA, L. E. Xamanismo amazônico, ayahuasca, antropomorfismo e mundo natural. In: LABATE, B.; ARAÚJO, W. (Ed.). O uso ritual da ayahuasca. Campinas: Mercado de Letras, 2009. p. 181-200.

MAGNANI, J. G. O xamanismo urbano e a religiosidade contemporânea. Religião e Sociedade, Rio de Janeiro, v. 20, n. 2, p. 113-140, 1999.

MIGNOLO, W. La idea de América Latina. Barcelona: Gedisa, 2007. 
MIGNOLO, W. Historias locales/diseños globales: colonialidad, conocimietos subalternos y pensamiento fronterizo. Madrid: Akal, 2013.

PRATT, M. L. Ojos imperiales: literatura de viajes y transculturación. Buenos Aires: FCE, 2011.

SCURO, J. Neochamanismo en América Latina: una cartografía desde el Uruguay. 2016. Tesis (Doctorado en Antropología Social)- Instituto de Filosofia e Ciências Humanas, Universidade Federal do Rio Grande do Sul, Porto Alegre, 2016.

SCURO, J.; RODD, R. Neo-Shamanism. In: GOOREN, H. (Ed.). Encyclopedia of Latin American religions. New York: Springer, 2015. p. 1-6.

STUCKRAD, K. Reenchanting nature: modern western shamanism and nineteenthcentury thought. Journal of the American Academy of Religion, v. 70, n. 4, p. 771-799, 2002.

TAUSSIG, M. Chamanismo, colonialismo y el hombre salvaje: un estudio sobre el terror y la curación. Bogotá: UC, 2012.

TEISENHOFFER, V. De la 'nebulosa místico-esotérica' al circuito alternativo. Miradas cruzadas sobre el new age y los nuevos movimientos religiosos. In: ARGYRIADIS, $\mathrm{K}$. et al. Raíces en movimiento: prácticas religiosas tradicionales en contextos translocales. México: IRD: ICESAS: CEMCA: ITESO: El Colegio de Jalisco, 2008. p. 45-72.

TONIOL, R. Nova Era e saúde: balanço e perspectivas teóricas. BIB, São Paulo, n. 80, p. 27-41, 2017.

VIVEIROS DE CASTRO, E. A inscostância da alma selvagem. São Paulo: Cosac Naify, 2002.

WINKELMAN, M. Psychointegrator plants: their role in human culture, consciousness and health. In: WINKELMAN, M; ANDRITZIKY, W. (Ed.). Sacred plants, consciousness, and healing: cross-cultural and interdisciplinary perspectives. Berlin: Verlag für Wissenschaft und Bildung, 1996. p. 9-53.

WINKELMAN, M. Shamanism: a biopsychosocial paradigm of consciousness and healing. Santa Barbara: Praeger, 2010.

ZNAMENSKI, A. The beauty of the primitive. New York: Oxford University Press, 2007.

Recebido: 31/05/2017 Aceito: 14/03/2018 | Received:31/5/2017 Accepted:3/14/2018 